\title{
Effect of Pressure and Hot Vapor Residence Time on the Fast Pyrolysis of Biomass: Experiments and Modeling
}

\author{
P. S. Marathe, R. J. M Westerhof, and S. R. A. Kersten*
}

Cite This: Energy Fuels 2020, 34, 1773-1780

Read Online

ABSTRACT: Pyrolysis of acid-leached bagasse $\left(515^{\circ} \mathrm{C}\right)$ and pinewood $\left(485^{\circ} \mathrm{C}\right)$ has been carried out in the pressure range from 5 $\times 10^{-3}$ to $100 \mathrm{kPa}$ in a screen-heater, designed for nearly isothermal operation and rapid quenching of reaction products. At the lowest pressure, i.e., by maximizing the escape rate of products away from the hot reaction zone, $73 \%$ of the poly- $\mathrm{C}_{6}$-sugars in bagasse were recovered in the liquid product as $\mathrm{C}_{6}$-anhydrosugars $\left(\mathrm{C}_{6} \mathrm{aS}\right)$ with degree of polymerization between 1 and $6\left(\mathrm{DP}_{1}\right.$ to $\mathrm{DP}_{6}$ ). A mathematical model, including reactions and mass transfer, was able to predict the measured decrease in the total yield of $\mathrm{C}_{6} \mathrm{aS}$ and the shift to lighter $\mathrm{C}_{6} \mathrm{aS}$ in the DP-distribution as a function of increasing pressure. The effect of the hot vapor residence time on the DP-distribution of the $\mathrm{C}_{6} \mathrm{aS}$ was investigated by pyrolyzing pinewood in a fluidized bed. At identical pressure (50 kPa) and temperature $\left(485{ }^{\circ} \mathrm{C}\right)$ the total yield of $\mathrm{C}_{6} \mathrm{aS}$ was the same for the screen-heater and fluidized bed while the DP-distribution shifted to $\mathrm{DP}_{1}$ as a result of the higher hot vapor residence time in the fluidized bed, which could be described by assuming first order kinetics for all possible cracking reactions of $\mathrm{C}_{6} \mathrm{aS}$ in the vapor phase.

\section{INTRODUCTION}

In numerous studies fast pyrolysis of biomass was studied as a function of the reactor temperatures (e.g., refs 1-6) but at a constant pressure, often $100 \mathrm{kPa}$. Contrarily, only few accounts were delivered on the pyrolysis of biomass at reduced pressure, ${ }^{7-16}$ and in most of these studies, ${ }^{7-10,12,13,16}$ pyrolysis was carried out at a single pressure. To the best of our knowledge, Amutio et al. ${ }^{11}$ and Pecha et al. ${ }^{14}$ did biomass pyrolysis experiments at several pressures. Amutio et al. ${ }^{11}$ operated a continuous conical spouted bed reactor at 25 and $100 \mathrm{kPa}$ for the pyrolysis of pine wood, from which they showed that the pressure has little effect on the yields of the lumped products liquid (oil), char, and gas. This was confirmed by us for bagasse (see Table S1 in the Supporting Information (SI)). Pecha et al. ${ }^{14}$ performed pyrolysis of poplar over a wide range of pressure $(0.4-100 \mathrm{kPa})$ and quantified monomeric, dimeric, and trimeric anhydrosugars present in the oil. They reported an increase in the $\mathrm{DP}_{1}$ (levoglucosan) yield of a factor of two, while the yield of larger anhydrosugars $\left(\mathrm{DP}_{2}\right.$, $\mathrm{DP}_{3}$, etc.) diminished when increasing the pressure.

Pyrolytic anhydrosugars (e.g., levoglucosan) are of interest because they can be upgraded to ethanol or platform chemicals. ${ }^{17-20}$ It is well-known that alkali and alkaline earth metals (AAEMs) show strong catalytic activity with respect to the pyrolysis reactions, particularly the decomposition of sugars. ${ }^{21-28}$ In fact, we observed less $\mathrm{C}_{6}$-anhydrosugars $\left(\mathrm{C}_{6} \mathrm{aS}\right)$ in the absolute sense and less strong trends between pressure and the yields of $\mathrm{DP}_{1}$ to $\mathrm{DP}_{6}$ for untreated (AAEMs-rich) pinewood and bagasse (see Figures $\mathrm{S} 1-\mathrm{S} 5$ in the SI) while clear trends were found for AAEMs lean feedstocks. Therefore, in order not to be hindered by these catalytic effects, AAEMs lean (acid-leached) pinewood and bagasse were used in this study. Both pinewood and bagasse were used to investigate if the feedstock itself influences the measured trends. We observed less $\mathrm{C}_{6} \mathrm{aS}$ in the absolute sense and less strong trends between pressure and the yields of $\mathrm{DP}_{1}$ to $\mathrm{DP}_{6}$ for untreated (AAEMs-rich) pinewood and bagasse.

In this paper, we investigate the effect of pressure and hot vapor residence time on the production of these anhydrosugars. This work aims primarily at advancing the understanding of the role of pressure during the fast pyrolysis of biomass. For this, experiments were performed in a broad pressure range ( 5 $\times 10^{-3}$ to $\left.100 \mathrm{kPa}\right)$ at 485 and $515^{\circ} \mathrm{C}$ in a screen-heater. This screen-heater ${ }^{29,30}$ was designed to ensure fast quenching of the products leaving the reacting biomass. Hence, in the screenheater, reactions in the hot vapor phase are minimized thereby facilitating the study of the chemistry and transfer processes at the particle level only. Experimentally obtained yields of $\mathrm{C}_{6} \mathrm{aS}$, obtained in the screen-heater, were compared with a mathematical model, ${ }^{30}$ which includes chemical reactions and transport of products away from the reaction zone. It is important to mention that it was not our intention to parametrize this model. Instead, the research question was as follows: If and under which assumptions does a model including chemistry and mass transfer predict the experimentally observed trends?

The second objective of this study is to investigate the cracking of $\mathrm{C}_{6} \mathrm{aS}$ in the vapor phase. Scott et al. and Graham et al. varied the hot $\left(700{ }^{\circ} \mathrm{C}\right)$ vapor residence time of the products between 30 and $900 \mathrm{~ms}$ during the pyrolysis of cellulose. $^{31,32}$ They observed that between 30 and $300 \mathrm{~ms}$, the

Received: September 18, 2019

Revised: January 5, 2020

Published: January 13, 2020 
gas yield increased at the expense of liquid products, and above $300 \mathrm{~ms}$ the lumped products yields remain constant. Hoekstra et al. performed the pyrolysis of pinewood in a fluidized bed at $500{ }^{\circ} \mathrm{C}$, in which the hot vapor residence time of products was varied between 1.5 and $16.5 \mathrm{s.}^{33}$ Upwards of $\sim 4.5 \mathrm{~s}$, the authors reported no change in the lumped product yields, while the levoglucosan yield was found constant over the entire range of hot vapor residence time. Like reported in previous studies, also in this work, a decrease in the oil yield was seen with increasing hot vapor residence time (Table S3 of the SI). We also performed pyrolysis experiments in a fluidized bed. In this reactor, reactions in the hot vapor phase do play a significant role. ${ }^{30,33,34}$ A comparison was made between pyrolysis experiments, performed at identical temperature and pressure, in the screen-heater $(\mathrm{SH})$ and fluidized bed (FB) in order to evaluate the influence of the hot vapor residence time $(20 \mathrm{~ms}$ in $\mathrm{SH}$ versus $1 \mathrm{~s}$ in $\mathrm{FB})$ on the product distribution, specifically the distribution of $\mathrm{C}_{6} \mathrm{aS}$.

\section{EXPERIMENTAL SECTION}

Materials. Pinewood $(0.5-2 \mathrm{~mm},<150 \mu \mathrm{m})$ was purchased from Rettenmaier \& Söhne $\mathrm{GmbH}$, and bagasse $(<150 \mu \mathrm{m})$ was kindly provided by Shell. Biomass samples were dried in an air-dried oven at $105{ }^{\circ} \mathrm{C}$ for $24 \mathrm{~h}$. Table 1 shows the total ash content and its

Table 1. Sugar Content, Total Ash Content, and Its Composition Present in the Biomass before and after Acid Leaching

\begin{tabular}{|c|c|c|c|c|}
\hline & \multicolumn{2}{|c|}{ bagasse } & \multicolumn{2}{|c|}{ pinewood } \\
\hline & untreated & acid-leached & untreated & acid-leached \\
\hline \multicolumn{5}{|c|}{ Compositional $^{a}$ ( $\mathrm{kg} \mathrm{kg}^{-1}$ Dry Ash and Extractive Free Biomass) } \\
\hline glucose & 0.49 & 0.5 & 0.53 & 0.53 \\
\hline xylose & 0.23 & 0.24 & 0.04 & 0.04 \\
\hline galactose & 0 & 0 & 0.01 & 0.01 \\
\hline arabinose & 0.03 & 0.02 & 0.01 & 0.01 \\
\hline mannose & 0 & 0.01 & 0.12 & 0.12 \\
\hline lignin & 0.25 & 0.23 & 0.29 & 0.29 \\
\hline \multicolumn{5}{|c|}{ Ash Analysis } \\
\hline $\operatorname{ash}^{b}($ wt $\%)$ & 1.85 & 0.59 & 0.43 & 0.10 \\
\hline $\mathrm{Na}^{+}\left(\mathrm{mg} \mathrm{kg}^{-1}\right)$ & 2657 & 100 & 37 & 10 \\
\hline $\mathrm{K}^{+}\left(\mathrm{mg} \mathrm{kg}^{-1}\right)$ & 1461 & 102 & 207 & 24 \\
\hline $\mathrm{Mg}^{2+}\left(\mathrm{mg} \mathrm{kg}^{-1}\right)$ & $-^{c}$ & - & 28 & 5 \\
\hline $\mathrm{Ca}^{2+}\left(\mathrm{mg} \mathrm{kg}^{-1}\right)$ & 914 & 37 & 277 & 26 \\
\hline Total $\left(\mathrm{mg} \mathrm{kg}^{-1}\right)$ & 5032 & 239 & 549 & 65 \\
\hline
\end{tabular}

${ }^{a}$ Taken from ref 28 . The composition analysis of biomass was performed by NREL LAP methods "Determination of Ethanol Extractives in Biomass" 35 and "Determination of Structural Carbohydrates and Lignin in Biomass". ${ }^{36}$ Including all inorganic materials (metals, Si, etc.). ${ }^{c}-$, not detected.

composition present in the biomass before and after acid leaching. The values reported in the table are the averages determined based on triplicates. It can be seen that the total ash content of bagasse and pinewood decreased after acid leaching by $68 \%$ and $77 \%$, respectively, while $95 \%$ and $88 \%$ removal of total AAEMs content for bagasse and pinewood was achieved, respectively.

Fast Pyrolysis. Screen-Heater. The screen-heater setup, its characteristics, and operating procedure are described in our previous work. ${ }^{29,30}$ The main characteristics of the screen-heater setup are presented in short here. The screens (thickness: $\sim 50 \mu \mathrm{m}$ ) with evenly distributed biomass $(\sim 50 \mathrm{mg})$ were heated to the final screen temperature $\left(T_{\mathrm{FS}}\right)$ at $\sim 5000{ }^{\circ} \mathrm{C} \mathrm{s}^{-1}$ to minimize nonisothermality. The $T_{\mathrm{FS}}$ was controlled within $\pm 15{ }^{\circ} \mathrm{C}$; for details refer to our previous work. ${ }^{29,30,34}$ The holding time of screens at the $T_{\mathrm{FS}}$ was $5 \mathrm{~s}$, and after that, they were cooled at a rate of $\sim 60{ }^{\circ} \mathrm{C} \mathrm{s}^{-1}$. The screens holding biomass were placed in a glass vessel which was cooled by liquid nitrogen $\left(-180^{\circ} \mathrm{C}\right)$. The estimated, ${ }^{30}$ by experiment and theory, hot vapor residence time is in the order of $20 \mathrm{~ms}$ for the whole pressure range, which ruled out a significant effect of vapor phase reactions taking place outside the reacting biomass particle. At the end of each experiment, independently determined oil, char, and gas yields were summed together to determine the overall mass balance closure. Experiments were carried out at $515^{\circ} \mathrm{C}$ for bagasse and at $485{ }^{\circ} \mathrm{C}$ for pinewood.

Fluidized Bed. Fast pyrolysis of pinewood was carried out in the continuous fluidized bed pilot plant, with a capacity of $1 \mathrm{~kg} \mathrm{~h}^{-1}$ biomass, of which details are described elsewhere. ${ }^{33,37}$ Therefore, the essential features of the setup and new modifications to operate the fluidized bed under vacuum will be presented here. All experiments were carried out in a nitrogen atmosphere. The pilot plant included two hoppers, one of which is used for storing biomass and the second for the sand. The feeding rates of biomass and sand (calibrated) screws were controlled by two different systems. A mixture of biomass and sand was fed to the fluidized bed reactor by using the third screw. In all experiments, the temperature of the fluidized bed reactor was maintained at $\sim 485{ }^{\circ} \mathrm{C}$. An overflow vessel was used to collect sand and char particles from the reaction zone. Solid particles, entrained with gas/vapors, were removed by a knocked out vessel and cyclones. The outlet of cyclones was connected to a jacketed electrostatic precipitator, where the temperature of the ESP condenser was maintained at $20^{\circ} \mathrm{C}$ (outgoing gas temperature). The products, which could not be condensed in ESP, were sent to a second condenser, also called an intensive cooler, operated at $-10^{\circ} \mathrm{C}$. The permanent gases passed through a gas filter to collect the remaining liquid. A vacuum pump, placed after the gas filter, was used to achieve lower pressure in the reactor, and it was controlled by a needle valve. The volumetric flow rate of the outgoing gas was measured by using a dry gas meter. All experiments were carried out for $90 \mathrm{~min}$, and at every $10 \mathrm{~min}$, a gas sample was taken from the outgoing gas stream. The composition of the outgoing gas was determined by a gas chromatograph. During all vacuum experiments, the pressure in the reactor was maintained at $50 \mathrm{kPa}$.

The main differences between screen-heater ${ }^{29,30}$ and fluidized bed $^{38}$ are summarized in Table 2 .

Table 2. Summary of Differences between Screen-Heater and Fluidized Bed

\begin{tabular}{lll} 
& \multicolumn{1}{c}{ screen-heater } & \multicolumn{1}{c}{ fluidized } \\
mode of operation & batch & continuous \\
$\begin{array}{l}\text { sample size } \\
\text { biomass particle size }\end{array}$ & $50 \mathrm{mg}$ & $1 \mathrm{~kg} \mathrm{~h}^{-1}$ \\
$(\mathrm{~mm})$ & $<0.15$ & $1-2$ \\
temperature $\left({ }^{\circ} \mathrm{C}\right)$ & 485 and 515 & \\
initial pressure $(\mathrm{kPa})$ & $5 \times 10^{-3}, 0.2,2,10,20,40,60,80$, & 50 \\
& 100 & 5000 \\
heating rate $\left({ }^{\circ} \mathrm{C} \mathrm{s}^{-1}\right)$ & 5000 & 1 \\
hot vapor residence time & 0.02 & \\
$(\mathrm{~s})$ & &
\end{tabular}

Mass Balance and Reproducibility. The mass balance closure of acid-leached bagasse (see Table 1 for characterization) pyrolysis experiments, performed in a screen-heater in a pressure range between $5 \times 10^{-3}$ and $100 \mathrm{kPa}$, was in the range $0.86-0.93 \mathrm{~kg} \mathrm{~kg}^{-1}$. Pyrolysis of acid-leached pinewood (see Table 1 for characterization) was carried out in a screen-heater $(0.2,50$, and $100 \mathrm{kPa})$ at $485^{\circ} \mathrm{C}$, of which the mass balance closures were in the range between 0.74 and $0.91 \mathrm{~kg} \mathrm{~kg}^{-1}$. An observed decrease in the mass balance closure, with an increase in pressure, can be ascribed to the observation that more pyrolysis products condensed on the gas sampling line, thermocouple, and pressure sensor line instead of on the cold vessel wall. Also, light organic compounds and water were most likely (partly) lost during gas sampling and the dismantling of the setup. However, it is 


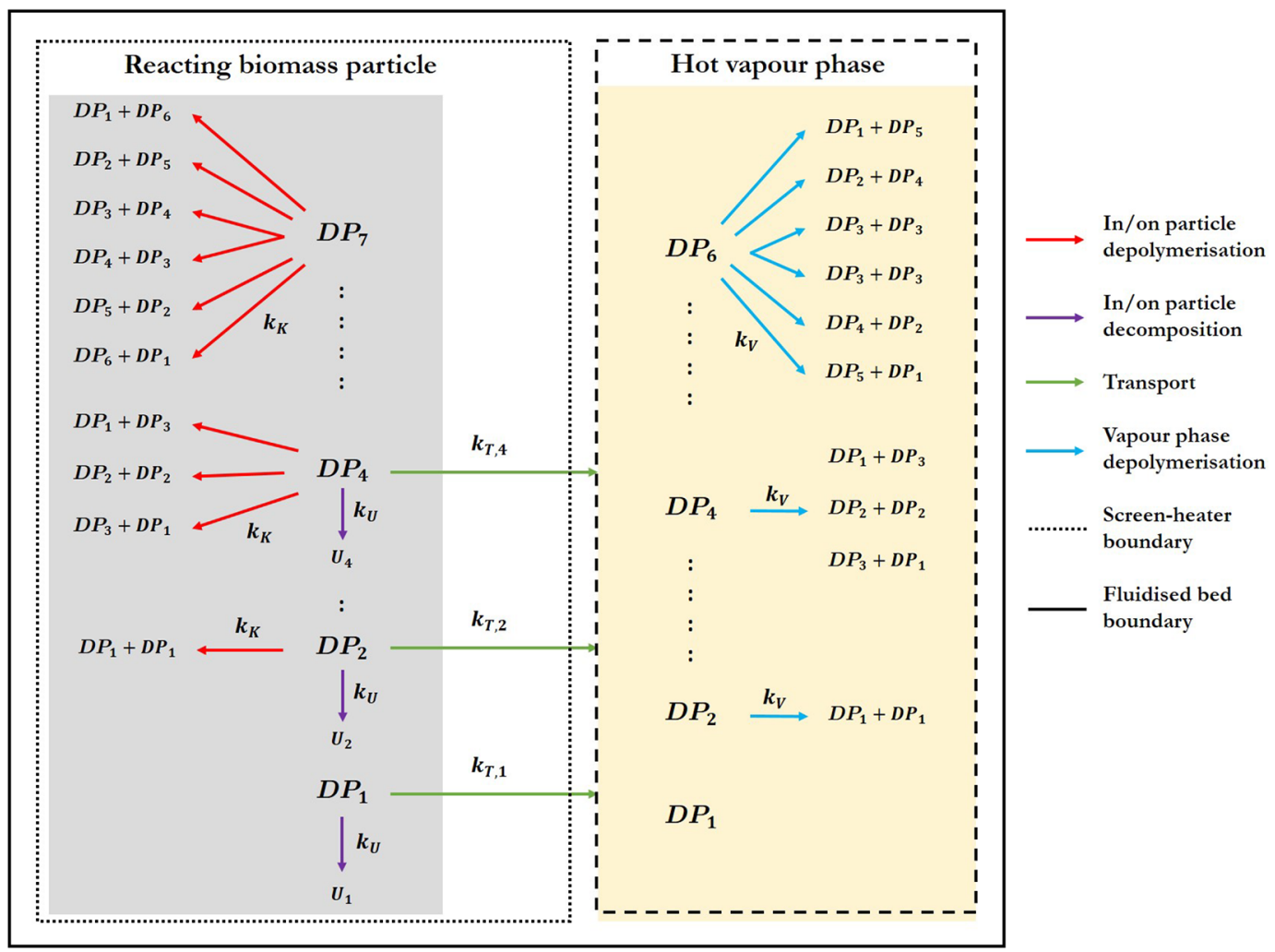

Figure 1. Schematic representation of the model.

important to note that no $\mathrm{C}_{6} \mathrm{aS}$ were lost. ${ }^{30}$ At least 3 experiments were performed for both feedstocks under identical conditions. Reproducibility of the experiments was satisfactory as shown in Tables S1 and S3 of the SI.

Because of the limited availability of acid-leached pinewood, only one pyrolysis experiment was performed, at $485{ }^{\circ} \mathrm{C}$ and $50 \mathrm{kPa}$, in the fluidized bed, of which mass balance closure was $0.94 \mathrm{~kg} \mathrm{~kg}^{-1}$. However, its reproducibility was judged by 5 pyrolysis experiments of untreated pinewood in the continuous fluidized bed at $485^{\circ} \mathrm{C}$ and 50 $\mathrm{kPa}$. The yields and standard deviation on the mean of wet oil, char, and gas were $0.62 \mathrm{~kg} \mathrm{~kg}^{-1}( \pm 0.01), 0.12 \mathrm{~kg} \mathrm{~kg}^{-1}( \pm 0.01)$, and $0.20 \mathrm{~kg}$ $\mathrm{kg}^{-1}( \pm 0.01)$. This shows that the reproducibility of experiments was satisfactory.

\section{METHODS}

Acid leaching of biomass was carried out using a synthetic mixture mimicking the second condenser liquid from the pyrolysis process, for details kindly refer to our previous work. ${ }^{27,28}$ The ash content of biomass samples (untreated and acid-leached) was determined by using the dry oxidation method. ${ }^{39}$

Analytical Techniques. The gas samples taken during the experiments were analyzed by a gas chromatograph (GC) twice to ensure reproducibility of product gases such as $\mathrm{CO}_{2}, \mathrm{CO}$, and $\mathrm{CH}_{4}$. The water-soluble fraction of the ash, dissolved in deionized water, was analyzed by ion chromatography (IC) to determine the AAEM content. For the details of GC and IC machines and chromatographic method settings, refer to our previous works. ${ }^{34}$ The yields of anhydrosugars, varying in degree of polymerization, were determined by using HPLC (see our previous work $\left.{ }^{30}\right)$. Levoglucosan (Carbosynth Ltd., purity >98\%), cellobiosan (Carbosynth Ltd., purity $>95 \%$ ), cellotriosan (LC Scientific, purity $>98 \%$ ), and celloterasan (LC Scientific, purity >98\%) were used as standards for the HPLC calibration. Deionized water was used to analyze the water-soluble fraction of the ash and the oil.

Modeling. The model, a modified version of our previously developed model for lignin fast pyrolysis, ${ }^{39}$ consists of population balances for the reacting $\mathrm{C}_{6} \mathrm{aS}$ on (in) the biomass particle and the reactions in the vapor phase. The schematic representation of the model is presented in Figure 1. The balances are made over segments called $\mathrm{DP}_{i}$ where $i$ refers to the number of monomer units out of which the molecules are built up. In a segment $\mathrm{DP}_{i}$, the $\mathrm{C}_{6} \mathrm{aS}$ molecules are identical linear polymers.

The following processes are considered for each segment. On (in) the particle, $\mathrm{C}_{6} \mathrm{aS}$ depolymerize (red arrows in Figure 1) to $\mathrm{C}_{6} \mathrm{aS}$ with a lower degree of polymerization, react to form other products $U$ (purple arrows), and escape from the reaction zone by mass transfer (green arrow). In the model, $U$ is a mathematical sink that represents the experimentally observed char, light volatile compounds, and gas (see Tables S1-S3 in the SI). This part of the model is called the particle model. For comparison with screen-heater reactions in the vapor phase that are not included (short hot vapor residence time, see Table 2), the particle model is thus used, while for the fluidized bed the whole model is used.

For these processes experimental proofs are available. Depolymerization reactions are evident from the presence of lower $\mathrm{DP}_{i}$ sugars in the oil (see Figures $\mathrm{S} 1-\mathrm{S} 5$ in the SI). The yield of $\mathrm{C}_{6} \mathrm{aS}$, at any given pressure investigated in this study, was $<1 \mathrm{~kg} \mathrm{~kg}^{-1} \mathrm{C}_{6}$ sugars, and char and gas were produced, thereby confirming the occurrence of decomposition reactions to $U$. Transport of molecules from the reaction zone is obvious as oil was collected at the cold vessel wall. The $\mathrm{DP}_{i}$ grid ranges from $i=1$ to $i=7$ in the simulations. $\mathrm{DP}_{1}-\mathrm{DP}_{6}$ represent $\mathrm{C}_{6} \mathrm{aS}$ on (in) the biomass particle and oil, while $\mathrm{DP}_{7}$ represents the initial state of the $\mathrm{C}_{6}$ in biomass because $\mathrm{C}_{6} \mathrm{aS}$ bigger than $\mathrm{DP}_{6}$ were not detected in collected oils (see Figures $\mathrm{S} 6-\mathrm{S} 8$ in the SI).

We do not claim that this model is complete and/or conclusive; we merely made an attempt to derive the simplest model possible that includes processes for which experimental proof is available and of which predictions can be compared to experimental data at the level of yields $\mathrm{C}_{6} \mathrm{aS}$. Also, as mentioned in the introduction, we did not attempt to parametrize the particle model in the absolute sense; instead the question is if and under which assumptions does this model describe the experimental results. 
Particle Model. Mass Balance. The normalized (normalized to the initial mass of the particle) mass balances for $\mathrm{DP}_{1}$ to $\mathrm{DP}_{7}$ and other products $(U)$ are presented below.

$$
\begin{aligned}
& \frac{\mathrm{d} m_{\mathrm{DP}_{i}}^{\mathrm{P}}}{\mathrm{d} t}=\left(K_{i}^{\mathrm{f}}-K_{i}^{\mathrm{c}}\right)-U_{i}-E_{i} \quad 1 \leq i \leq 6 \\
& \frac{\mathrm{d} m_{\mathrm{DP}_{i}}^{\mathrm{P}}}{\mathrm{d} t}=K_{i}^{\mathrm{c}} \quad i=7 \\
& \frac{\mathrm{d} m_{U}}{\mathrm{~d} t}=\sum_{i=1}^{6} U_{i} \\
& \frac{\mathrm{d} m_{\mathrm{DP}}^{\mathrm{OS}}}{\mathrm{d} t}=E_{i} \quad 1 \leq i \leq 6
\end{aligned}
$$

Here, $m_{\mathrm{DP}_{i}}^{\mathrm{P}}$ is the mass of $\mathrm{DP}_{i}$ at the particle, $m_{U}$ is the mass of other products at the particle, $m_{\mathrm{DP}_{i}}{ }^{\mathrm{OS}}$ is mass of $\mathrm{DP}_{i}$ in screen-heater oil, $K_{i}^{f}$ is net rate of formation of $\mathrm{DP}_{i}, K_{i}^{\mathrm{c}}$ is net rate of consumption of $\mathrm{DP}_{i}$, $U_{i}$ is rate of decomposition of $\mathrm{DP}_{i}$, and $E_{i}$ is rate of transport of $\mathrm{DP}_{i}$.

Depolymerization. Depolymerization is assumed to be a first order process, and all reactions have the same likelihood; i.e., the rate constant $k_{K}$, is the same for all depolymerization reactions. For details of eqs 5 and 6 see the previously published work of Solomon et al. ${ }^{40,41}$ and Marathe et al. ${ }^{39}$ Note that $\mathrm{DP}_{1}$ does not depolymerize further.

$$
\begin{gathered}
K_{i}^{\mathrm{f}}=k_{\mathrm{K}} 2 \sum_{j=i+1}^{7}{ }_{j}^{i} m_{\mathrm{DP}_{j}}^{\mathrm{P}} \quad 1 \leq i \leq 6 \\
K_{i}^{\mathrm{c}}=k_{K}(i-1) m_{\mathrm{DP}_{i}}^{\mathrm{P}} \quad 1 \leq i \leq 6
\end{gathered}
$$

Decomposition. Decomposition reactions of $\mathrm{C}_{6} \mathrm{aS}$ to $U$ are also assumed to follow first order kinetics and to have the same rate constant $\left(k_{U}\right)$. It is assumed that $U$, once formed, do not take part in any reactions. Whether or not $U$ stays on the particle is of no concern for this study. It is assumed that $\mathrm{DP}_{7}$ does not decompose to form $U$, however, assuming that the decomposition of $\mathrm{DP}_{7}$ does not affect the outcome.

$$
U_{i}=k_{U} m_{\mathrm{DP}_{i}}^{\mathrm{P}} \quad 1 \leq i \leq 6
$$

Transport. The transport of $\mathrm{C}_{6} \mathrm{aS}$ by evaporation/sublimation/ ejection is described by eq 8 . Note that $k_{\mathrm{T}, \text { avg }}$ is a simple average of the transport rate of individual $\mathrm{C}_{6} \mathrm{aS}$ varying in DP between 1 and 6 , and it is calculated by eq 9 .

$$
\begin{aligned}
& E_{i}=k_{\mathrm{T}, i} m_{\mathrm{DP}_{i}}^{\mathrm{P}}=\mathrm{e}^{-A i} m_{\mathrm{DP}_{i}}^{\mathrm{P}} \quad 1 \leq i \leq 6 \\
& k_{\mathrm{T}, \text { avg }}=\frac{\sum_{i=1}^{6} k_{\mathrm{T}, i}}{6}
\end{aligned}
$$

Initial Conditions. The initial normalized masses of $\mathrm{C}_{6} \mathrm{aS}\left(\mathrm{DP}_{1}\right.$ to $\left.\mathrm{DP}_{6}\right)$ on the hot reacting particle and in the screen-heater oil are

$$
m_{\mathrm{DP}_{i}, t=0}^{\mathrm{P}}=m_{\mathrm{DP}_{i}, t=0}^{\mathrm{OS}}=0 \quad 1 \leq i \leq 6
$$

The mass fraction of $\mathrm{C}_{6}$ sugars $\left(f_{\mathrm{C}}\right)$ present in bagasse or pinewood is used as an initial normalized mass of $\mathrm{DP}_{7}$ (see Table 1).

$$
m_{\mathrm{DP}_{i}, t=0}^{\mathrm{P}}=f_{\mathrm{C}_{6}} \quad i=7
$$

The normalized mass of other products $(U)$ is

$$
m_{U, t=0}=0
$$

Postprocessing. Equations 10 and 11 calculate the yield of $\mathrm{C}_{6} \mathrm{aS}$ and the mass fraction of $\mathrm{DP}_{1}$ in $\mathrm{C}_{6} \mathrm{aS}$, respectively.

$$
Y_{\mathrm{C}_{6} \mathrm{~S}, \mathrm{cal}, t=\infty}=\frac{\sum_{i=1}^{6} m_{\mathrm{DP}_{i}, t=\infty}^{\mathrm{OS}}}{m_{\mathrm{DP}_{7}, t=0}^{\mathrm{P}}}
$$

$$
f_{\mathrm{DP}_{1}, \mathrm{cal}, t=\infty}=\frac{m_{\mathrm{DP}_{1}, t=\infty}^{\mathrm{OS}}}{\sum_{i=1}^{6} m_{\mathrm{DP}_{i}, t=\infty}^{\mathrm{OS}}}
$$

Parameter Estimation.

$$
\begin{aligned}
& h_{j}=\sum\left\{\left(f_{\mathrm{DP}_{1}, \exp }-f_{\mathrm{DP}_{1}, \mathrm{cal}, t=\infty}\right)^{2}+\left(Y_{\mathrm{C}_{6} \mathrm{aS}, \exp }-Y_{\mathrm{C}_{6} \mathrm{aS}, \mathrm{cal}, t=\infty}\right)^{2}\right\} \\
& g=\sum_{j=1}^{n} h_{j}
\end{aligned}
$$

The objective function (eq 12) is comprised of (1) the sum of the squared difference between the experimentally obtained and calculated mass fraction of $\mathrm{DP}_{1}$ in $\mathrm{C}_{6} \mathrm{aS}$ and (2) the squared difference between the experimentally obtained and calculated $\mathrm{C}_{6} \mathrm{aS}$ yield. The subscript $j$ in eqs 12 and 13 represents the objective function calculated for each pressure, $j$.

Hot Vapor Phase. Mass Balance. The normalized mass balances for $\mathrm{DP}_{1}$ to $\mathrm{DP}_{6}$ in the hot vapor phase are presented below, in which $m_{\mathrm{DP}_{i}}^{\mathrm{OFB}}$ is the mass of $\mathrm{DP}_{i}$ in fluidized bed oil.

$$
\frac{\mathrm{d} m_{\mathrm{DP}_{i}}^{\mathrm{OFB}}}{\mathrm{d} t}=k_{V}\left[2 \sum_{j=i+1}^{6} \frac{i}{j} m_{\mathrm{DP}_{i}}^{\mathrm{OFB}}-(i-1) m_{\mathrm{DP}_{i}}^{\mathrm{OFB}}\right] \quad 1 \leq i \leq 6
$$

Initial Conditions. The DP-distribution of $\mathrm{C}_{6} \mathrm{aS}$ in the fluidized bed could not be measured after $\sim 20 \mathrm{~ms}$. Therefore, the experimentally obtained DP-distribution of $\mathrm{C}_{6} \mathrm{aS}$ in the screen-heater is used as the initial conditions, as follows:

$$
\begin{aligned}
& m_{\mathrm{DP}_{1}, t=0}^{\mathrm{OFB}}=0.076, m_{\mathrm{DP}_{2}, t=0}^{\mathrm{OFB}}=0.115, m_{\mathrm{DP}_{3}, t=0}^{\mathrm{OFB}}=0.056, m_{\mathrm{DP}_{4}, t=0}^{\mathrm{OFB}} \\
& \quad=0.02, m_{\mathrm{DP}_{5}, t=0}^{\mathrm{OFB}}=0.003, m_{\mathrm{DP}_{6}, t=0}^{\mathrm{OFB}}=0.003
\end{aligned}
$$

\section{Parameter Estimation.}

$$
h=\sum\left(m_{\mathrm{DP}_{i}, \exp }^{\mathrm{OFB}}-m_{\mathrm{DP}_{i}, \text { cal }, t=\tau}^{\mathrm{OFB}}\right)^{2}
$$

The objective function for this (eq 15) is composd of the sum of the squared difference between the experimentally obtained (in fluidized bed) and calculated (after the hot vapor residence time, $\tau=$ $1 \mathrm{~s})$ normalized masses of $\mathrm{DP}_{1}$ to $\mathrm{DP}_{6}$. The experimental DPdistribution of $\mathrm{C}_{6} \mathrm{aS}$ was fitted to the model to obtain the value of $k_{V}$. Parameter estimation is carried out with the Matlab built-in optimization function 1sqnonlin. The $95 \%$ confidence interval for $k_{V}$ was determined by the built-in Matlab function nlparci.

Numerical Method. The model equations were implemented in the coding environment of Matlab2017a. The numerical integration was carried out with the built-in ode45 solver which is based on the explicit Runge-Kutta method. This model can also be solved analytically by finding the eigenvalues and eigenvectors of the system. The resulting equations, however, turned out to be very large and did not yield sets of parameters that gave enhanced insight in the behavior of the system. The analytical solution of the $\mathrm{DP}_{3}$ to $\mathrm{DP}_{1}$ system (excluding hot vapor phase reactions) is presented in Section S3 of the SI.

Note that the experimental method (in the screen-heater) does not allow the determination of the temporal evolution of products. Instead, final yields $(t=\infty)$ are obtained, which leads to the restriction that it is not possible to determine all three constants $\left(k_{\mathrm{T}, \text { avg }}, k_{U}\right.$, and $\left.k_{\mathrm{K}}\right)$ by fitting them to the experimental results. It is only possible to determine two ratios between the three parameters (refer to Section S3 of the SI). We selected $\frac{k_{K}}{k_{K}+k_{U}}$ and $\frac{k_{\mathrm{T}, \text { avg }}}{k_{K}+k_{U}}$.

Vapor phase depolymerization reactions of $\mathrm{C}_{6} \mathrm{aS}$ are also assumed to be first order, and all possibilities have the same likelihood, i.e., the same rate constant $k_{V}$. For interpretation of the screen-heater experiments only $k_{\mathrm{T} \text {,avg }} k_{U}$, and $k_{K}$ are considered, while for the fluidized bed $k_{V}$ is included, which can be regressed in an absolute sense. 


\section{RESULTS AND DISCUSSION}

Anhydrosugars. In this section, the $\mathrm{C}_{6} \mathrm{aS}$ yields obtained from bagasse and pinewood are discussed. The HPLC chromatograms of the water-soluble fraction of pyrolysis oil were integrated as described elsewhere. ${ }^{30}$ The presence of up to $\mathrm{DP}_{6}$ sugars in the oil, obtained from bagasse and pinewood, was confirmed by the direct infusion mass spectrometry (Figures S6-S8 in the SI).

It is worth mentioning that, from the pyrolysis of Avicel $\mathrm{PH}$ $101, \mathrm{C}_{6} \mathrm{aS}$ with DP up to 11 were found in the oil, ${ }^{42-47}$ whereas from bagasse and pinewood, $\mathrm{DP}_{6}$ was the biggest detected $\mathrm{C}_{6} \mathrm{aS}$. This difference might be explained by the structural differences between the Avicel PH 101 and native cellulose. In this line of reasoning, In bagasse and pinewood, the $\mathrm{C}_{6} \mathrm{aS}$ escape rate is lower because of the hindrance created by the lignin present in the cell wall of the bagasse and pinewood particle as compared to Avicel PH 101. As a result of which, bigger $\mathrm{C}_{6} \mathrm{aS}$ undergo depolymerization reactions to form smaller DP $\mathrm{C}_{6} \mathrm{aS}$. Moreover, Avicel PH 101 is one of the purest forms of cellulose, and hence, its pyrolysis is not affected by lignin or any other contaminant (e.g., AAEMs). In the literature, during the pyrolysis of bagasse and pinewood, the presence of $\mathrm{C}_{6} \mathrm{aS}$ up to $\mathrm{DP}_{3}$ in the oil is reported, ${ }^{23,24,48,49}$ while we are the first, to the best of our knowledge, to report the presence of up to $\mathrm{DP}_{6} \quad \mathrm{C}_{6} \mathrm{aS}$ from the bagasse and pinewood pyrolysis. The presence of bigger $\mathrm{C}_{6} \mathrm{aS}$ (up to $\mathrm{DP}_{6}$ ) in biomass-derived oils emphasizes the role of random scission of native cellulose, which was previously concluded for microcrystalline cellulose; ${ }^{42-47}$ however, the unzipping mechanism, proposed by Golova et al., ${ }^{50}$ still cannot be excluded from running in addition to random scission.

Effect of Pressure in Screen-Heater Experiments. In Figure 2, the total yield of $\mathrm{C}_{6} \mathrm{aS}$ (expressed on the fraction of $\mathrm{C}_{6}$ sugars in bagasse/pinewood) and the mass fraction of $\mathrm{DP}_{1}$ in $\mathrm{C}_{6} \mathrm{aS}$ are plotted against the pressure. These experiments were carried out at a constant $T_{\mathrm{FS}}$ of $515{ }^{\circ} \mathrm{C}$ for bagasse and $485{ }^{\circ} \mathrm{C}$ for pinewood. At $5 \times 10^{-3} \mathrm{kPa}, 73 \%$ of $\mathrm{C}_{6}$ sugars from biomass were converted to $\mathrm{C}_{6} \mathrm{aS}$ during pyrolysis. Upon increasing the pressure to $10 \mathrm{kPa}$, the yield of total $\mathrm{C}_{6} \mathrm{aS}$

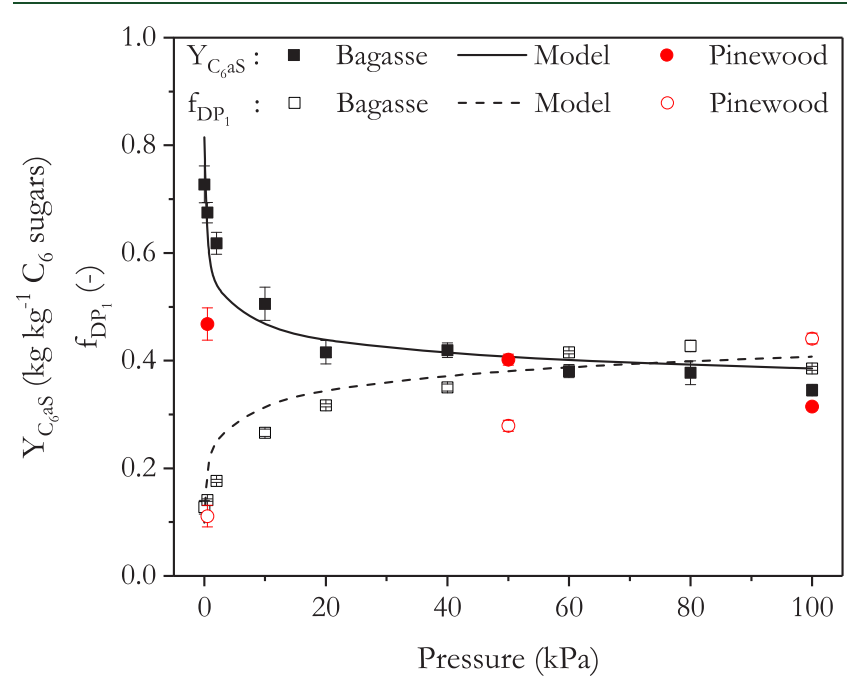

Figure 2. $\mathrm{C}_{6} \mathrm{aS}$ yield (eq 10) and $\mathrm{DP}_{1}$ mass fraction (eq 11) for acidleached bagasse and pinewood as a function of pressure: bagasse, $T_{\mathrm{FS}}$ $=515 \pm 15^{\circ} \mathrm{C}$; pinewood, $T_{\mathrm{FS}}=485 \pm 15^{\circ} \mathrm{C}$. In the model for acidleached bagasse, eq 16 (see Table 3 ) was used to describe the $k_{T, \text { avg }}$. dropped to the value of $\sim 0.5 \mathrm{~kg} \mathrm{~kg}^{-1}$, and upward of $20 \mathrm{kPa}$, only a small decrease in the yield to $\sim 0.42 \mathrm{~kg} \mathrm{~kg}^{-1}$ was observed. The mass fraction of $\mathrm{DP}_{1}$ increased as a function of pressure from 0.13 to $\sim 0.42$. It is worth mentioning that, even at $100 \mathrm{kPa}$, the major fraction of the $\mathrm{C}_{6} \mathrm{aS}$ is composed of $\mathrm{DP}_{\geq 2}$ $\mathrm{C}_{6} \mathrm{aS}$. Note that, between 10 and $20 \mathrm{kPa}$, a step change in the yield of $\mathrm{C}_{6} \mathrm{aS}$ (or $\mathrm{DP}_{1}$ mass fraction) was observed. Between 20 and $100 \mathrm{kPa}$, the yield remained (nearly) constant, while the $\mathrm{DP}_{1}$ mass fraction increases from 0.32 to $\sim 0.41$. This trend is in line with the results of Pecha et al., ${ }^{14}$ who reported an increase in the $\mathrm{DP}_{1}$ (levoglucosan) yield (on poplar wood basis) from $0.06 \mathrm{~kg} \mathrm{~kg}^{-1}(0.4 \mathrm{kPa})$ to $0.1 \mathrm{~kg} \mathrm{~kg}^{-1}(100 \mathrm{kPa})$, while the yield of $\mathrm{DP}_{2}$ and $\mathrm{DP}_{3} \mathrm{C}_{6}$ aS diminished. Similar trends were observed for acid-leached pinewood, though less pronounced $\mathrm{C}_{6} \mathrm{aS}$ yield increased at low pressure, as shown in Figure S2 and Table S4 in the SI.

To support the interpretation of the experimentally observed trends the model was used without cracking in the vapor phase, i.e., $k_{V}=0$, which is a valid assumption for the screenheater. $^{29,42}$ An attempt was made to fit a single $\frac{k_{K}}{k_{K}+k_{U}}$ and $\frac{k_{\mathrm{T}, \text { avg }}}{k_{\mathrm{K}}+k_{U}}$ for all pressures, which is referred to as the total fit procedure (for values see Table 3 ). This resulted in a poor

Table 3. Values of $\frac{k_{K}}{k_{K}+k_{U}}, \frac{k_{\mathrm{T}, \text { avg }}}{k_{K}+k_{U}}$, and $k_{V}$ Obtained Using the Individual Fit Procedure

\begin{tabular}{|c|c|c|c|}
\hline & $\frac{k_{T, a v g}}{k_{K}+k_{U}}$ & $\frac{k_{K}}{k_{K}+k_{U}}$ & $k_{V}$ \\
\hline & - & - & \\
\hline \multicolumn{4}{|c|}{ Bagasse $^{a}$} \\
\hline Screen-heater & $1.9( \pm 0.9)^{\mathrm{c}}-0.4( \pm 0.1)^{\mathrm{c}}$ & $0.3^{\mathrm{d}}$ & - \\
\hline \multicolumn{4}{|c|}{ Correlation between $\frac{k_{T, a v g}}{k_{K}+k_{U}}$ and pressure } \\
\hline \multicolumn{4}{|c|}{ Pinewood ${ }^{b}$} \\
\hline Screen-heater & $0.3( \pm 0.05)^{\mathrm{c}}$ & $0.1( \pm 0.01)^{\mathrm{c}}$ & - \\
\hline Fluidised bed & - & - & $0.8( \pm 0.1)^{\mathrm{c}}$ \\
\hline \multicolumn{4}{|c|}{$\begin{array}{l}{ }^{a} \text { Pressures }(\mathrm{kPa}): 5 \times 10^{-3}, 0.2,2,10,20,40,60,80,100 .{ }^{b} \text { Pressure } \\
(\mathrm{kPa}): 50 .{ }^{c} \text { Values in parentheses are the } 95 \% \text { confidence intervals on } \\
\text { the ratios. }{ }^{d} \text { Value of } \frac{k_{K}}{k_{K}+k_{U}} \text { from the total fit procedure used in the } \\
\text { individual fit procedure to estimate } \frac{k_{\mathrm{T}, \text { avg }}}{k_{K}+k_{U}} \text { per pressure. }\end{array}$} \\
\hline
\end{tabular}

prediction of the yield of $\mathrm{C}_{6} \mathrm{aS}$ and the $\mathrm{DP}_{1}$ mass fraction (Figure $\mathrm{S} 15$ in the $\mathrm{SI}$ ) because the escape rate of $\mathrm{C}_{6} \mathrm{aS}$ is a function of pressure, and hence, a single value of $\frac{k_{T, a v g}}{k_{K}+k_{U}}$ cannot capture it.

Next, $\frac{k_{K}}{k_{K}+k_{U}}$ obtained from the total fit procedure was set to a fixed value [which is rationalized by the fact that the measurement was done at a single temperature and the pressure independence of $k_{K}$ and $k_{U}$ (first order reactions)], to obtain $\frac{k_{T, a v g}}{k_{K}+k_{U}}$ per pressure, which is called the individual fit 
procedure. The values of $\frac{k_{\mathrm{T}, \text { avg }}}{k_{K}+k_{U}}$ obtained from the individual fit procedure decreased as a function of increasing pressure. The range of fitted $\frac{k_{\mathrm{T}, \text { avg }}}{k_{\mathrm{K}}+k_{U}}$ (individual fit) is presented in Table 3, and in Table S7 of the SI they are listed per pressure with their $95 \%$ confidence intervals. With the fitted $\frac{k_{\mathrm{T}, \text { arg }}}{k_{\mathrm{K}}+k_{U}}$ as a function of pressure (Figure S17 in the SI) and fixed $\frac{k_{K}}{k_{K}+k_{U}}$ (obtained from total fit procedure), the model predicted the experimentally observed trends correctly (Figure 2). Measurements and model prediction show that the interplay between depolymerization reactions and mass transfer plays an important role in the fast pyrolysis of acid-leached biomass.

Effect of Hot Vapor Residence Time. Figure 3 presents the DP-distribution obtained from the pyrolysis of pinewood at

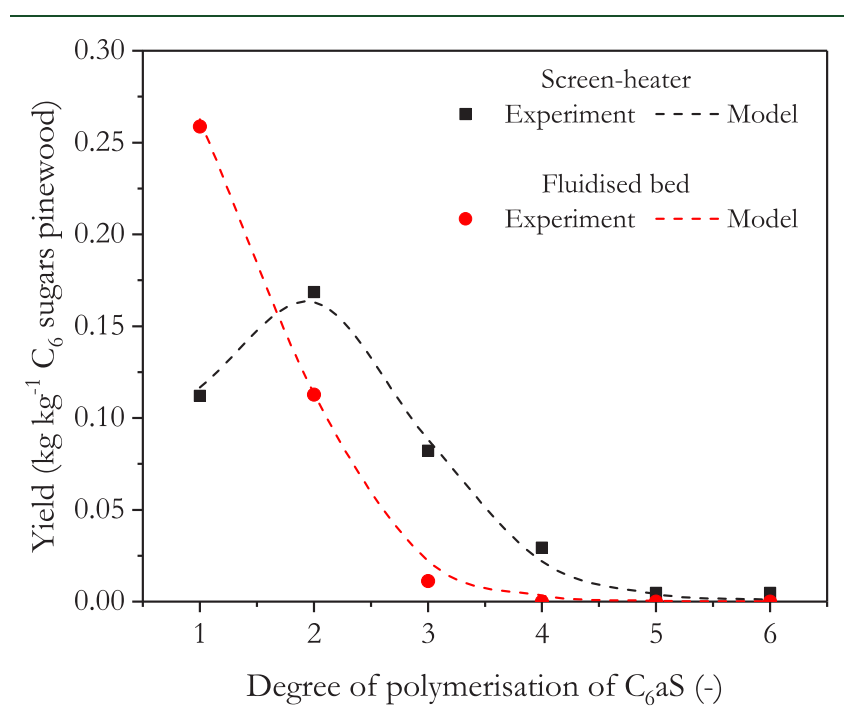

Figure 3. DP-distribution of anhydrosugar (experimental and calculated) on the $\mathrm{C}_{6}$ sugars basis, obtained from pyrolysis of acidleached pinewood at $485{ }^{\circ} \mathrm{C}$ and $50 \mathrm{kPa}$ in the screen-heater and fluidized bed.

$485{ }^{\circ} \mathrm{C}$ and $50 \mathrm{kPa}$ in the screen-heater and fluidized bed. As can be seen, the $\mathrm{C}_{6} \mathrm{aS}$ in the fluidized bed oil were predominantly composed of $\mathrm{DP}_{1}$ and $\mathrm{DP}_{2}$, while bigger $\mathrm{C}_{6} \mathrm{aS}$ $\left(\mathrm{DP}_{\geq 3}\right)$ were present in small or trace quantities. Contrarily, the yield of $\mathrm{DP}_{1}$ observed in the screen-heater was a factor of $\sim 2$ lower compared to the fluidized bed oils, while the yield of $\mathrm{DP}_{2}$ was highest $\left(\sim 0.17 \mathrm{~kg} \mathrm{~kg}^{-1} \mathrm{C}_{6}\right.$ sugars $)$. The cumulative yield of $\mathrm{DP}_{3}$ and $\mathrm{DP}_{4} \mathrm{C}_{6} \mathrm{aS}$ was $\sim 0.1 \mathrm{~kg} \mathrm{~kg}^{-1} \mathrm{C}_{6}$ sugars, and the presence of $\mathrm{DP}_{>4} \mathrm{C}_{6} \mathrm{aS}$ was marginal. However, it is important to mention that, despite a significant difference in the DPdistribution, the total yield of $\mathrm{C}_{6} \mathrm{aS}$ from the screen-heater and the fluidized bed was $\sim 0.39 \mathrm{~kg} \mathrm{~kg}^{-1} \mathrm{C}_{6}$ sugars. This also supports our hypothesis that we can model the fluidized bed by a particle model (input from screen-heater measurement) in combination with a model for the hot vapor phase.

At an identical pressure, it is fair to assume that the mass transport rate of products away from the reacting biomass particle is identical in the screen-heater and fluidized bed. Assuming that, the remarkable difference in the DPdistribution can be ascribed solely to the different hot vapor residence time of products in these two reactors: the screenheater $(\sim 20 \mathrm{~ms})$ and the fluidized bed $(\sim 1 \mathrm{~s})$. Since the DP- distribution of $\mathrm{C}_{6} \mathrm{aS}$ in the fluidized bed could not be measured after $\sim 20 \mathrm{~ms}$, the experimentally obtained DP-distribution in the screen-heater is used as the model input for vapor phase cracking reactions. Fitting the vapor phase cracking reaction rate constant to a value of $k_{v}=0.8 \pm 0.1 \mathrm{~s}^{-1}$ accurately predicted the DP-distribution observed in the fluidized bed (see Figure 3). Note that, for the prediction of the $\mathrm{C}_{6} \mathrm{aS}$ DPdistribution for the screen-heater experiment of acid-leached pinewood, shown in Figure 3, newly fitted values for acidleached pinewood are presented in Table 3.

Gathered experimental evidence shows that the bigger $\mathrm{C}_{6} \mathrm{aS}$ $\left(\mathrm{DP}_{>2}\right)$ undergo depolymerization reactions in the hot vapor phase to form smaller DP $\mathrm{C}_{6} \mathrm{aS}$ and reconfirms the previously reported claim that $\mathrm{DP}_{1}$ anhydrosugar is thermally stable in the time scale of a few seconds. ${ }^{33,51}$ Moreover, an observed increase in the gas yield for fluidized bed experiments can be ascribed only to the decomposition of volatile products (e.g., light oxygenated compounds) in the hot vapor phase leading to lower oil yields, which is rationalized by the experimentally obtained similar total yield $\mathrm{C}_{6} \mathrm{aS}$ yields in the screen-heater and fluidized bed.

\section{CONCLUSIONS}

In this paper, the effect of pressure on the fast pyrolysis of acidleached bagasse and pinewood is studied in a dedicated screenheater (heating rate $\sim 5000{ }^{\circ} \mathrm{C} \mathrm{s}^{-1}$, fast quenching at $\sim-180$ $\left.{ }^{\circ} \mathrm{C}, \mathrm{T}=485-515{ }^{\circ} \mathrm{C}\right)$, while varying the system pressure $(5 \times$ $10^{-3}$ to $\left.100 \mathrm{kPa}\right)$. It was found that, (1) at the lowest pressure, $73 \%$ of the poly- $\mathrm{C}_{6}$-sugars in bagasse were recovered in the liquid product as $\mathrm{C}_{6}$-anhydrosugars $\left(\mathrm{C}_{6} \mathrm{aS}\right)$, while the mass fraction of $\mathrm{DP}_{1}$ was only $10 \%$ and, (2) with increasing pressure, upwards of $20 \mathrm{kPa}$, the yield of $\mathrm{C}_{6} \mathrm{aS}$ reached a plateau value of $\sim 40 \%$, and a shift toward lighter $\mathrm{C}_{6} \mathrm{aS}$ in the DP-distribution was observed. A mathematical model, including depolymerization and decomposition reactions of $\mathrm{C}_{6} \mathrm{aS}$, and mass transport, could predict, after parametrization, the effect of pressure on the yield of $\mathrm{C}_{6} \mathrm{aS}$ and the $\mathrm{DP}_{1}$ mass fraction in the DP-distribution. Modeling results show that the pressure strongly affects the mass transport of products away from the hot reacting particle, consequently, changing the likelihood of chemical reactions on/in the particle.

Pyrolysis (at $485{ }^{\circ} \mathrm{C}$ and $50 \mathrm{kPa}$ ) of acid-leached pinewood in the screen-heater and fluidized bed resulted in the similar total yields of $\mathrm{C}_{6} \mathrm{aS}$ with distinctively different DP-distribution, the former being richer in larger $\mathrm{C}_{6} \mathrm{aS} \mathrm{DP} \mathrm{P}_{>2}$ than the latter. As a result of the long hot vapor residence time (screen-heater $\sim 20 \mathrm{~ms}$ vs fluidized bed $\sim 1 \mathrm{~s}$ ), other volatile species (e.g., light oxygenated compounds) decompose to gas (or water) leading to lower oil yields, and depolymerization of bigger $\mathrm{C}_{6} \mathrm{aS}$ $\left(\mathrm{DP}_{\geq 2}\right)$ takes place to form lower DP $\mathrm{C}_{6} \mathrm{aS}$.

\section{ASSOCIATED CONTENT}

\section{SI Supporting Information}

The Supporting Information is available free of charge at https://pubs.acs.org/doi/10.1021/acs.energyfuels.9b03193.

Additional data and figures including $\mathrm{DP}_{i}$ yield, mass spectra, schematic, $\mathrm{C}_{6} \mathrm{aS}$ yield, and a parity plot (PDF)

\section{AUTHOR INFORMATION}

\section{Corresponding Author}

S. R. A. Kersten - Sustainable Process Technology (SPT), Department of Science and Technology (TNW), University of 
Twente 7522 NB Enschede, The Netherlands; 으이.org/ 0000-0001-8333-2649; Phone: +31-53-489 4430;

Email: s.r.a.kersten@utwente.nl; Fax: +31-53-489 4738

\section{Authors}

P. S. Marathe - Sustainable Process Technology (SPT), Department of Science and Technology (TNW), University of Twente 7522 NB Enschede, The Netherlands

R. J. M Westerhof - Sustainable Process Technology (SPT), Department of Science and Technology (TNW), University of Twente 7522 NB Enschede, The Netherlands

Complete contact information is available at:

https://pubs.acs.org/10.1021/acs.energyfuels.9b03193

\section{Notes}

The authors declare no competing financial interest.

\section{ACKNOWLEDGMENTS}

The authors thank Thomas Derks and Julia Kharisma Putri Shaliha for their contribution to a part of the experimental work. Additionally, the authors acknowledge the technical staff of the SPT group (Benno Knaken and Johan Agterhorst) for their excellent technical support. This work is financially supported by NWO (Project number -717-014-006), The Netherlands to which authors are grateful.

\section{NOMENCLATURE}

\section{Symbols}

$A=(-)$ parameter used to describe the transport rate of $\mathrm{DP}_{i}$

$E_{i}=\left(\mathrm{s}^{-1}\right)$ transport rate of $\mathrm{DP}_{i}$ from the reacting particle to cold glass wall at $t=t$

$f_{C 6}=(-)$ fraction of $\mathrm{C}_{6}$ sugars in biomass

$f_{\mathrm{DP}_{1} \text { exp }}=(-)$ experimentally obtained mass fraction of $\mathrm{DP}_{1}$ in $\mathrm{C}_{6} \mathrm{aS}$

$f_{\mathrm{DP}_{1}, \mathrm{cal}, t=\infty}=(-)$ calculated mass fraction of $\mathrm{DP}_{6}$ in $\mathrm{C}_{1} \mathrm{aS}$ at $t$ $=\infty$

$K_{i}=\left(\mathrm{s}^{-1}\right)$ overall depolymerization rate of $\mathrm{DP}_{i}$ at $t=t$

$k_{\mathrm{T}, i}=\left(\mathrm{s}^{-1}\right)$ evaporation/sublimation/ejection rate constant of $\mathrm{DP}_{i}$

$k_{K}=\left(\mathrm{s}^{-1}\right)$ first order depolymerization rate constant

$k_{U}=\left(\mathrm{s}^{-1}\right)$ first order decomposition rate constant

$k_{V}=\left(\mathrm{s}^{-1}\right)$ first order vapor phase depolymerization rate constant

$m_{\mathrm{DP}_{i}}^{\mathrm{P}}=(-)$ normalized mass of $\mathrm{DP}_{i}$ at the reacting particle at $t=t$

$m_{\mathrm{DP}_{i} t=0}^{\mathrm{P}}=(-)$ normalized mass of $\mathrm{DP}_{i}$ at the reacting particle at $t=0$

$m_{\mathrm{DP}_{i}}^{\mathrm{O}}=(-)$ normalized mass of $\mathrm{DP}_{i}$ at the cold glass wall at $t$ $=t$

$m_{\mathrm{DP}_{i}, t=0}^{\mathrm{O}}=(-)$ normalized mass of $\mathrm{DP}_{i}$ in screen-heater oil at $t=0$

$m_{\mathrm{DP}_{i}, t=\infty}^{\mathrm{O}}=(-)$ normalized mass of $\mathrm{DP}_{i}$ in screen-heater oil at $t=\infty$

$m_{\mathrm{DP}}^{\mathrm{OFB}}=(-)$ normalized mass of $\mathrm{DP}_{i}$ in fluidized bed oil at $t$ $=t$

$m_{\mathrm{DP}}^{\mathrm{OFB}} \mathrm{O}_{i \mathrm{exp}}=(-)$ experimentally obtained normalized mass of $\mathrm{DP}_{i}$ in fluidized bed oil

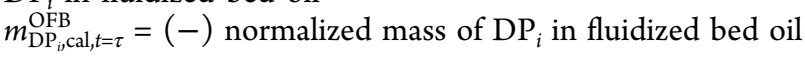
at $t=\tau$

$U_{i}=\left(\mathrm{s}^{-1}\right)$ overall decomposition rate of $\mathrm{DP}_{i}$ at $t=t$

$m_{U}=(-)$ normalized mass of other products at $t=t$
$Y_{\mathrm{C} 6 \mathrm{aS}, \exp }=\left(\mathrm{kg} \mathrm{kg}^{-1}\right)$ experimentally obtained yield of $\mathrm{C}_{6} \mathrm{aS}$

$Y_{\mathrm{C} 6 \mathrm{aS}, \mathrm{cal}, t=\infty}=\left(\left(\mathrm{kg} \mathrm{kg}^{-1}\right)\right.$ calculated yield of $\mathrm{C}_{6} \mathrm{aS}$ at $t=\infty$

\section{Superscripts}

$$
\begin{aligned}
& c=\text { consumption } \\
& \mathrm{f}=\text { formation }
\end{aligned}
$$

\section{Definition of Normalized Mass}

$$
\begin{aligned}
& m_{\mathrm{DP}_{i}}^{\mathrm{P}}=\frac{\text { mass of } \mathrm{DP}_{i} \text { at the particle }}{\text { total initial particle mass }} \\
& m_{U}=\frac{\text { mass of other products }}{\text { total initial particle mass }} \\
& m_{\mathrm{DP}}^{\mathrm{OS}}=\frac{\text { mass of } \mathrm{DP}_{i} \text { in screen }- \text { heater oil }}{\text { total initial particle mass }} \\
& m_{\mathrm{DP}}^{\mathrm{OFB}}=\frac{\text { mass of } \mathrm{DP}_{i} \text { in fluidized bed oil }}{\text { total initial particle mass }}
\end{aligned}
$$

\section{REFERENCES}

(1) Garcia-Perez, M.; Wang, S.; Shen, J.; Rhodes, M.; Lee, W. J.; Li, C.-Z. Effects of Temperature on the Formation of Lignin-Derived Oligomers during the Fast Pyrolysis of Mallee Woody Biomass. Energy Fuels 2008, 22, 2022-2032.

(2) Liaw, S.-S.; Wang, Z.; Ndegwa, P.; Frear, C.; Ha, S.; Li, C.-Z.; Garcia-Perez, M. Effect of pyrolysis temperature on the yield and properties of bio-oils obtained from the auger pyrolysis of Douglas Fir wood. J. Anal. Appl. Pyrolysis 2012, 93, 52-62.

(3) Oudenhoven, S. R. G.; Lievens, C.; Westerhof, R. J. M.; Kersten, S. R. A. Effect of temperature on the fast pyrolysis of organic-acid leached pinewood: the potential of low temperature pyrolysis. Biomass Bioenergy 2016, 89, 78-90.

(4) Rover, M. R.; Johnston, P. A.; Whitmer, L. E.; Smith, R. G.; Brown, R. C. The effect of pyrolysis temperature on recovery of biooil as distinctive stage fractions. J. Anal. Appl. Pyrolysis 2014, 105, 262-268.

(5) Wang, Z.; Zhou, S.; Pecha, B.; Westerhof, R. J. M.; Garcia-Perez, M. Effect of Pyrolysis Temperature and Sulfuric Acid During the Fast Pyrolysis of Cellulose and Douglas Fir in an Atmospheric Pressure Wire Mesh Reactor. Energy Fuels 2014, 28, 5167-5177.

(6) Montoya, J.; Pecha, B.; Roman, D.; Janna, F. C.; Garcia-Perez, M. Effect of temperature and heating rate on product distribution from the pyrolysis of sugarcane bagasse in a hot plate reactor. J. Anal. Appl. Pyrolysis 2017, 123, 347-363.

(7) Roy, C.; Caumia, B. D.; Pakdel, H. Research in Thermochemical Biomass Conversion; Springer Netherlands, 1988; pp 585-596.

(8) Pakdel, H.; Roy, C.; Amen-Chen, C.; Roy, C. Phenolic compounds from vacuum pyrolysis of wood wastes. Can. J. Chem. Eng. 1997, 75, 121-126.

(9) Garcia-Perez, M.; Chaala, A.; Pakdel, H.; Kretschmer, D.; Roy, C. Vacuum pyrolysis of softwood and hardwood biomass. J. Anal. Appl. Pyrolysis 2007, 78, 104-116.

(10) Garcia-Perez, M.; Chaala, A.; Roy, C. Vacuum pyrolysis of sugarcane bagasse. J. Anal. Appl. Pyrolysis 2002, 65, 111-136.

(11) Amutio, M.; Lopez, G.; Aguado, R.; Artetxe, M.; Bilbao, J.; Olazar, M. Effect of Vacuum on Lignocellulosic Biomass Flash Pyrolysis in a Conical Spouted Bed Reactor. Energy Fuels 2011, 25, 3950-3960.

(12) Nunn, T. R.; Howard, J. B.; Longwell, J. P.; Peters, W. A. Product compositions and kinetics in the rapid pyrolysis of sweet gum hardwood. Ind. Eng. Chem. Process Des. Dev. 1985, 24, 836-844.

(13) Hoekstra, E.; Van Swaaij, W. P. M.; Kersten, S. R. A.; Hogendoorn, K. J. A. Fast pyrolysis in a novel wire-mesh reactor: Decomposition of pine wood and model compounds. Chem. Eng. J. 2012, 187, 172-184.

(14) Pecha, M. B.; Terrell, E.; Montoya, J. I.; Stankovikj, F.; Broadbelt, L. J.; Chejne, F.; Garcia-Perez, M. Effect of Pressure on Pyrolysis of Milled Wood Lignin and Acid-Washed Hybrid Poplar Wood. Ind. Eng. Chem. Res. 2017, 56, 9079-9089.

(15) Chen, N.; Ren, J.; Ye, Z.; Xu, Q.; Liu, J.; Sun, S. Study on vacuum pyrolysis of coffee industrial residue for bio-oil production. 
IOP Conference Series: Earth and Environmental Science 2017, 59, 012065 .

(16) Ju, Y. M.; Oh, K. C.; Lee, K. Y.; Kim, D. H. Performance Analysis of a Vacuum Pyrolysis System. Journal of Biosystems Engineering 2018, 43, 14-20.

(17) Gallo, J. M. R.; Alonso, D. M.; Mellmer, M. A.; Dumesic, J. A. Production and upgrading of 5-hydroxymethylfurfural using heterogeneous catalysts and biomass-derived solvents. Green Chem. 2013, $15,85-90$.

(18) Gärtner, C. A.; Serrano-Ruiz, J. C.; Braden, D. J.; Dumesic, J. A. Catalytic upgrading of bio-oils by ketonization. ChemSusChem 2009, 2, 1121-1124.

(19) Hu, X.; Li, C.-Z. Levulinic esters from the acid-catalysed reactions of sugars and alcohols as part of a bio-refinery. Green Chem. 2011, 13, 1676.

(20) Luque, L.; Westerhof, R.; Rossum, G. V.; Oudenhoven, S.; Kersten, S.; Berruti, F.; Rehmann, L. Pyrolysis based bio-refinery for the production of bioethanol from demineralized ligno-cellulosic biomass. Bioresour. Technol. 2014, 161, 20-28.

(21) Piskorz, J.; Radlein, D. S. A. G.; Scott, D. S.; Czernik, S. Pretreatment of wood and cellulose for production of sugars by fast pyrolysis. J. Anal. Appl. Pyrolysis 1989, 16, 127-142.

(22) Scott, D. S.; Paterson, L.; Piskorz, J.; Radlein, D. Pretreatment of poplar wood for fast pyrolysis: rate of cation removal. J. Anal. Appl. Pyrolysis 2001, 57, 169-176.

(23) Radlein, D.; Piskorz, J.; Grinshpun, A.; Scott, D. Fast pyrolysis of pre-treated wood and cellulose. J. Anal. Appl. Pyrolysis 1987, 12, 39-49.

(24) Brown, R. C.; Radlein, D.; Piskorz, J. In ACS Symposium Series; Bozell, J. J., Ed.; ACS Symposium Series; American Chemical Society: Washington, DC, 2001; pp 123-132.

(25) Mourant, D.; Wang, Z.; He, M.; Wang, X. S.; Garcia-Perez, M.; Ling, K.; Li, C.-Z. Mallee wood fast pyrolysis: Effects of alkali and alkaline earth metallic species on the yield and composition of bio-oil. Fuel 2011, 90, 2915-2922.

(26) Kuzhiyil, N.; Dalluge, D.; Bai, X.; Kim, K. H.; Brown, R. C. Pyrolytic sugars from cellulosic biomass. ChemSusChem 2012, 5, 2228-2236.

(27) Oudenhoven, S. R. G.; Westerhof, R. J. M.; Aldenkamp, N.; Brilman, D. W. F.; Kersten, S. R. A. Demineralization of wood using wood-derived acid: towards a selective pyrolysis process for fuel and chemicals production. J. Anal. Appl. Pyrolysis 2013, 103, 112-118.

(28) Oudenhoven, S. R. G.; Westerhof, R. J. M.; Kersten, S. R. A. Fast pyrolysis of organic acid leached wood, straw, hay and bagasse: improved oil and sugar yields. J. Anal. Appl. Pyrolysis 2015, 116, 253262.

(29) Hoekstra, E.; van Swaaij, W. P. M.; Kersten, S. R. A.; Hogendoorn, K. J. A. Fast pyrolysis in a novel wire-mesh reactor: design and initial results. Chem. Eng. J. 2012, 191, 45-58.

(30) Westerhof, R. J. M.; Oudenhoven, S. R. G.; Marathe, P. S.; Engelen, M.; Garcia-Perez, M.; Wang, Z.; Kersten, S. R. A. The interplay between chemistry and heat/mass transfer during the fast pyrolysis of cellulose. Reaction Chemistry \& Engineering 2016, 1, 555566.

(31) Scott, D. S.; Piskorz, J.; Bergougnou, M. A.; Graham, R.; Overend, R. P. The role of temperature in the fast pyrolysis of cellulose and wood. Ind. Eng. Chem. Res. 1988, 27, 8-15.

(32) Graham, R. G.; Bergougnou, M. A.; Freel, B. A. The kinetics of vapour-phase cellulose fast pyrolysis reactions. Biomass Bioenergy 1994, 7, 33-47.

(33) Hoekstra, E.; Westerhof, R. J. M.; Brilman, W.; Swaaij, W. P. V.; Kersten, S. R. A.; Hogendoorn, K. J. A.; Windt, M. Heterogeneous and homogeneous reactions of pyrolysis vapors from pine wood. AIChE J. 2012, 58, 2830-2842.

(34) Marathe, P. S.; Oudenhoven, S. R. G.; Heerspink, P. W.; Kersten, S. R. A.; Westerhof, R. J. M. Fast pyrolysis of cellulose in vacuum: The effect of potassium salts on the primary reactions. Chem. Eng. J. 2017, 329, 187-197.
(35) Sluiter, A.; Ruiz, R.; Scarlata, C.; Sluiter, J.; Templeton, D. Determination of Extractives in Biomass; tech report NREL/TP-51042618, 2008.

(36) Sluiter, A.; Hames, B.; Ruiz, R.; Scarlata, C.; Sluiter, J.; Templeton, D.; Crocker, D. Determination of Structural Carbohydrates and Lignin in Biomass; tech report NREL/TP-510-42619, 2008.

(37) Westerhof, R. J. M.; Brilman, D. W. F. W.; van Swaaij, W. P. M.; Kersten, S. R. A. Effect of Temperature in Fluidized Bed Fast Pyrolysis of Biomass: Oil Quality Assessment in Test Units. Ind. Eng. Chem. Res. 2010, 49, 1160-1168.

(38) Westerhof, R. J. M.; Brilman, D. W. F.; Garcia-Perez, M.; Wang, Z.; Oudenhoven, S. R. G.; van Swaaij, W. P. M.; Kersten, S. R. A. Fractional Condensation of Biomass Pyrolysis Vapors. Energy Fuels 2011, 25, 1817-1829.

(39) Marathe, P. S.; Westerhof, R. J. M.; Kersten, S. R. A. Fast pyrolysis of lignins with different molecular weight: Experiments and modelling. Appl. Energy 2019, 236, 1125-1137.

(40) Avni, E.; Coughlin, R. W.; Solomon, P. R.; King, H. H. Mathematical modelling of lignin pyrolysis. Fuel 1985, 64, 14951501.

(41) Solomon, P. R.; King, H.-H. Tar evolution from coal and model polymers: Theory and experiments. Fuel 1984, 63, 1302-1311.

(42) Oudenhoven, S. R. G. Improving the selectivity of pyrolysis by pyrolytic acid leaching of biomass: the role of AAEMs, anhydrosugar production and process design \& evaluation. Ph.D. Thesis, University of Twente, 2016

(43) Pouwels, A. D.; Eijkel, G. B.; Arisz, P. W.; Boon, J. J. Evidence for oligomers in pyrolysates of microcrystalline cellulose. J. Anal. Appl. Pyrolysis 1989, 15, 71-84.

(44) Piskorz, J.; Radlein, D.; Scott, D. S. On the mechanism of the rapid pyrolysis of cellulose. J. Anal. Appl. Pyrolysis 1986, 9, 121-137.

(45) Piskorz, J.; Majerski, P.; Radlein, D.; Vladars-Usas, A.; Scott, D. S. Flash pyrolysis of cellulose for production of anhydro-oligomers. $J$. Anal. Appl. Pyrolysis 2000, 56, 145-166.

(46) Lédé, J.; Blanchard, F.; Boutin, O. Radiant flash pyrolysis of cellulose pellets: products and mechanisms involved in transient and steady state conditions. Fuel 2002, 81, 1269-1279.

(47) Radlein, D.; Piskorz, J.; Scott, D. Fast pyrolysis of natural polysaccharides as a potential industrial process. J. Anal. Appl. Pyrolysis 1991, 19, 41-63.

(48) Piskorz, J.; Majerski, P.; Radlein, D.; Scott, D. S.; Bridgwater, A. V. Fast pyrolysis of sweet sorghum and sweet sorghum bagasse. J. Anal. Appl. Pyrolysis 1998, 46, 15-29.

(49) Scott, D. S.; Majerski, P.; Piskorz, J.; Radlein, D. A second look at fast pyrolysis of biomass - the RTI process. J. Anal. Appl. Pyrolysis 1999, 51, 23-37.

(50) Golova, O. P. Chemical Effects of Heat on Cellulose. Russ. Chem. Rev. 1975, 44, 687-697.

(51) Hosoya, T.; Kawamoto, H.; Saka, S. Different pyrolytic pathways of levoglucosan in vapor-and liquid/solid-phases. J. Anal. Appl. Pyrolysis 2008, 83, 64-70. 